\title{
Early pre-eclampsia unmasks underlying IgA nephropathy
}

This article was published in the following Dove Press journal:

Pathology and Laboratory Medicine International

15 December 2010

Number of times this article has been viewed

\author{
Mona Singh \\ Akhenaton Pappoe \\ Burl R Don \\ Division of Nephrology, University \\ of California Davis Medical Center, \\ Sacramento, CA, USA
}

\begin{abstract}
Pre-eclampsia is the most ominous complication of pregnancy, and primary glomerular diseases can mimic pre-eclampsia in presentation. A patient presented at 21 weeks gestation with signs and symptoms of both pre-eclampsia and primary glomerular nephropathy. A critical clinical decision whether to continue or terminate the pregnancy was dependent on results of a renal biopsy. The biopsy noted the presence of both pre-eclampsia and immunoglobulin A (IgA) nephropathy. Thus, the onset of pre-eclampsia unmasked the presence of unrecognized IgA nephropathy, and the IgA nephropathy was a risk factor for this patient developing pre-eclampsia. The results of a renal biopsy are key in distinguishing pre-eclampsia from other kidney diseases and instituting appropriate clinical management.

Keywords: proteinuria, IgA nephropathy, renal biopsy, pre-eclampsia
\end{abstract}

\section{Introduction}

Pre-eclampsia is defined as a systemic syndrome unique to pregnancy, characterized by hypertension, proteinuria, edema, and at times liver abnormalities. ${ }^{1,2}$ Risk factors for pre-eclampsia include prior history of pre-eclampsia, first pregnancy, multiple gestation, pre-existing hypertension, renal disease, diabetes mellitus, family history of pre-eclampsia, obesity, advanced maternal age, and history of antiphospholipid syndrome. ${ }^{2}$ Pre-eclampsia usually begins after 32 weeks of gestation, but may begin as early as 20 weeks. ${ }^{2,3}$ If there are signs of hypertension, renal dysfunction, and edema developing prior to 32 weeks of gestation, a pre-existing kidney disease should also be considered. ${ }^{2}$ We report a case of a 45 -year-old woman without any prior history of renal disease or hypertension presenting at 22 weeks gestation with sudden onset of edema, hypertension, nephrotic-range proteinuria, elevated serum uric acid levels, and mild hematuria, who underwent a renal biopsy to confirm the clinical diagnosis of pre-eclampsia.

\section{Case report Clinical history and initial laboratory data}

A 45-year-old Asian woman was seen at her family physician's office for her first routine prenatal visit at 21 weeks gestation. She described having sudden onset of lower extremity swelling $\sim 3-4$ days prior to her clinic visit. The initial evaluation noted a blood pressure of $217 / 106 \mathrm{mmHg}$ and $4+$ proteinuria on urinary dipstick. The patient was admitted urgently to a local hospital where she was treated with intravenous hydralazine, labetalol, and magnesium sulfate. She was subsequently transferred
Correspondence: Burl R Don

Division of Nephrology, University of California Davis Medical Center, 4150 V Street, Suite 3500, Sacramento, CA 95817, USA

$\mathrm{Tel}+19167347961$

Fax+l 9167347920

Email br.don@ucdmc.ucdavis.edu
Pathology and Laboratory Medicine International 20 I I:3 I-5

(C) 20I I Singh et al, publisher and licensee Dove Medical Press Ltd. This is an Open Access article which permits unrestricted noncommercial use, provided the original work is properly cited. 
the next day to University of California Davis Medical Center for admission to the high-risk obstetrical service.

The patient's past medical history was significant for gestational diabetes during two prior pregnancies and one prior spontaneous abortion at 8 weeks. She denied any history of renal disease, hypertension, or prior history of pre-eclampsia.

On physical examination, her blood pressure was 153/76 mmHg. Pertinent findings included a soft, nontender gravid abdomen, 2+ pitting edema of her lower extremities, and $1+$ deep tendon reflexes bilaterally. The fetal heart rate was noted to be 122 beats $/ \mathrm{min}$. Serum chemistry values were as follows: sodium, $146 \mathrm{mmol} / \mathrm{L}$; potassium, $4.2 \mathrm{mmol} / \mathrm{L}$; chloride, $105 \mathrm{mmol} / \mathrm{L}$; bicarbonate, $24 \mathrm{mmol} / \mathrm{L}$; blood urea nitrogen, $14 \mathrm{mg} / \mathrm{dL}(5.0 \mathrm{mmol} / \mathrm{L})$; creatinine, $1.10 \mathrm{mg} / \mathrm{dL}$ (97.2 $\mu \mathrm{mol} / \mathrm{L})$; calcium, $7.8 \mathrm{mg} / \mathrm{dL}$ (1.95 mmol/L); phosphorus, $5.5 \mathrm{mg} / \mathrm{dL}$ (1.78 mmol/L); and uric acid, $6.2 \mathrm{mg} / \mathrm{dL}$ $(368 \mu \mathrm{mol} / \mathrm{L})$. The white blood cell (WBC) count was $11,800 / \mu \mathrm{L}$, hemoglobin $9.2 \mathrm{~g} / \mathrm{dL}$, hematocrit $27.9 \%$, and platelet count $189,000 / \mathrm{mm}^{3}$. The clinical laboratory urinalysis of a specimen obtained from an indwelling Foley catheter revealed a $\mathrm{pH} 5.0,4+$ protein and blood on the urinary dipstick. Microscopic examination of the urine sediment noted 50-100 red blood cells (RBCs) and three WBCs per high-powered field (HPF). Ultrasound imaging of the abdomen revealed a live intrauterine gestation with abnormal thickened placental appearance and decreased diastolic flows involving the umbilical artery and mid cerebral artery, suggestive of pre-eclampsia. The patient was continued on intravenous magnesium sulfate in addition to oral nifedipine and labetalol for management of her hypertension. Over the next 2 days, her abdominal distention increased and the lower extremity edema worsened. Repeat abdominal ultrasound revealed accumulation of ascites. The patient's serum creatinine increased to $1.19 \mathrm{mg} / \mathrm{dL}(105.2 \mu \mathrm{mol} / \mathrm{L})$, and a 24-h urine collection contained $7.76 \mathrm{~g}$ of protein.

Given the early onset of her clinical pre-eclampsia, the rapidity of accumulation of ascites and edema, and evidence of severe proteinuria, the nephrology service was consulted. Examination of the urine sediment revealed many nondysmorphic appearing RBCs per HPF. Serologic evaluation for possible glomerulonephritis noted a negative antinuclear antibody, antidouble-stranded DNA antibody, hepatitis $\mathrm{C}$ antibody, hepatitis B surface antigen, antiphospholipid antibody, and human immunodeficiency virus antibody. Serum complement levels were within normal limits. A repeat serum uric acid level remained elevated at $6.5 \mathrm{mg} / \mathrm{dL}(387 \mu \mathrm{mol} / \mathrm{L})$.
Because of the risks to the patient and viability of the fetus this early in gestation, a critical therapeutic decision was needed to either terminate or continue the pregnancy based on whether the patient had pre-eclampsia versus a primary kidney disease. Thus, a percutaneous renal biopsy was performed under ultrasound guidance.

\section{Kidney biopsy}

There were at least 20 glomeruli in the histologic sections. Four glomeruli were completely sclerotic. Most of the remaining glomeruli demonstrated abnormalities. Many glomeruli displayed extensive wrinkling of capillary loop basement membranes with epithelial cell hypertrophy and swollen endothelial cells (Figure 1). A few were noted to have segmental mesangial proliferation and a few demonstrated fuscinophilic deposits within the mesangium at the light microscopic level. Rare double-contoured capillary loop basement membranes were also seen. Definitive fibrin thrombi were not present within capillary loops. One glomerulus demonstrated a cellular crescent partially filling the urinary space (Figure 2). The tubulointerstitium demonstrated focal fibrosis, mild edema, and scattered interstitial lymphocytes. Tubules demonstrated occasional proteinaceous casts and occasional necrotic material within their lumens. Immunofluorescence microscopy demonstrated granular staining of the mesangium for immunoglobulin A (IgA) (4+) (Figure 3). Electron microscopy noted extensive wrinkling of the capillary loops and endothelial cell swelling (Figure 4). The mesangium was expanded and contained extensive collections of electron-dense granular material (Figure 5).

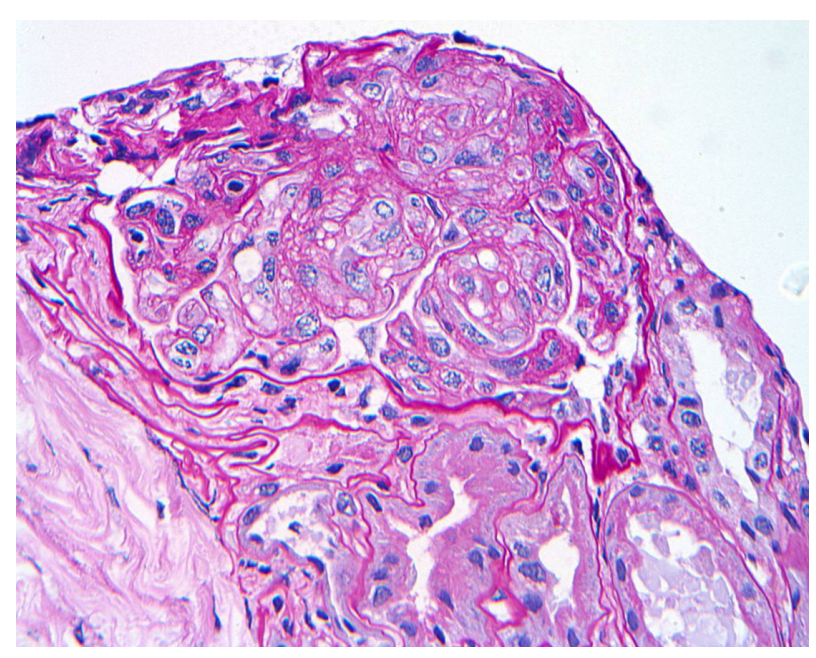

Figure I Photomicrograph of the patient's renal biopsy stained with hematoxylin and eosin. The glomerulus demonstrates swollen endothelial cells and epithelial cell hypertrophy consistent with a diagnosis of pre-eclampsia (original magnification $\times 400$ ). 


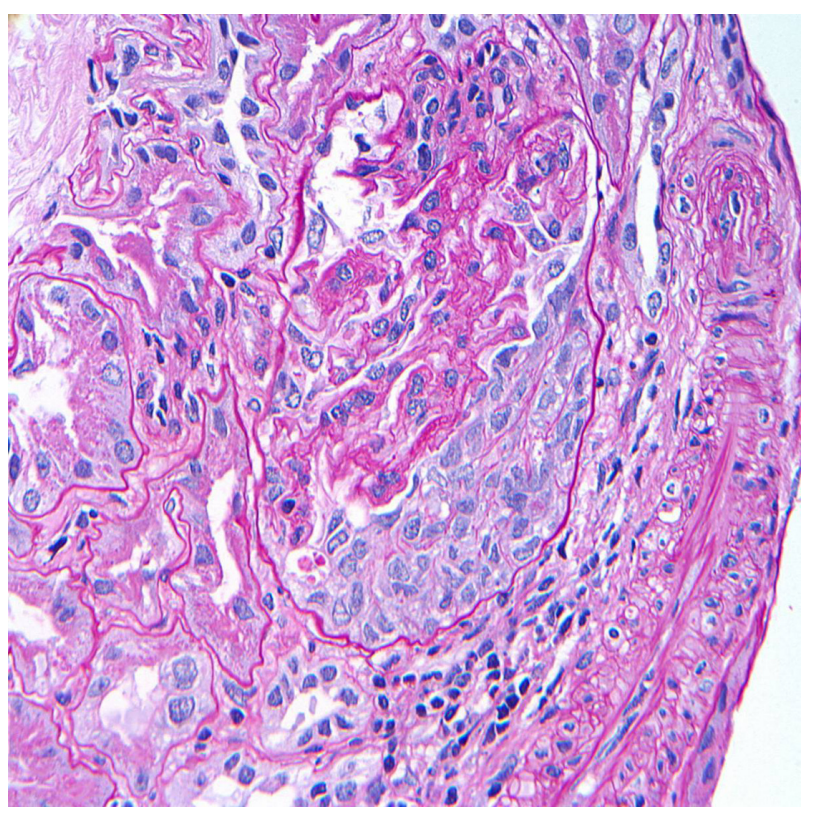

Figure 2 Photomicrograph of the patient's renal biopsy stained with hematoxylin and eosin. The glomerulus has a cellular crescent consistent with a diagnosis of glomerulonephritis (original magnification $\times 400$ ).

\section{Diagnosis}

Pre-eclampsia superimposed on IgA nephropathy.

\section{Clinical follow-up}

The patient tolerated the biopsy well with no alterations in blood pressure or other adverse events. The day following the biopsy, a repeat fetal ultrasound was performed revealing findings consistent with fetal demise. She underwent a spontaneous vaginal delivery the next day. Her abdominal distension and lower extremity swelling significantly

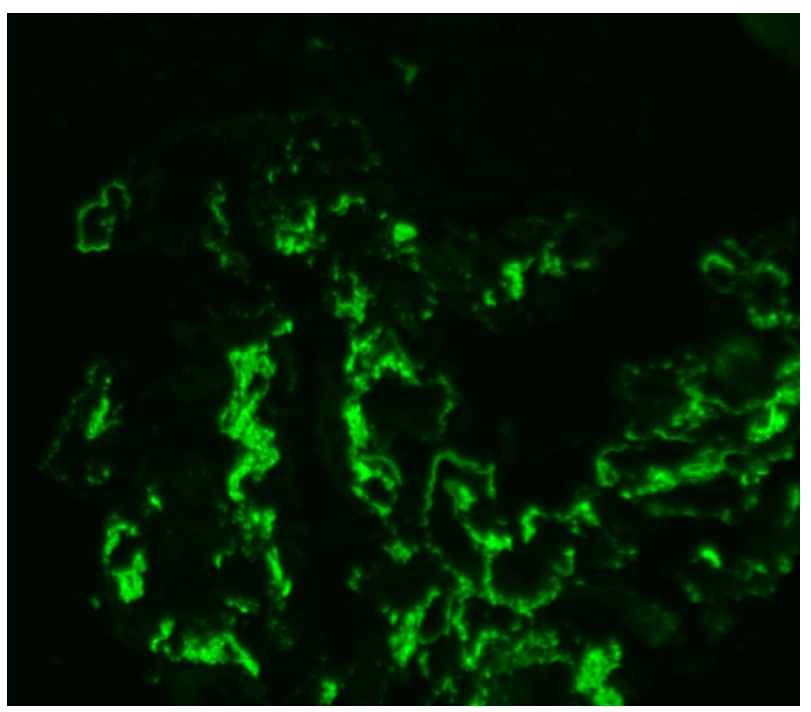

Figure 3 Immunofluorescence microscopy demonstrating granular staining of the mesangium for $\lg \mathrm{A}(4+)$.

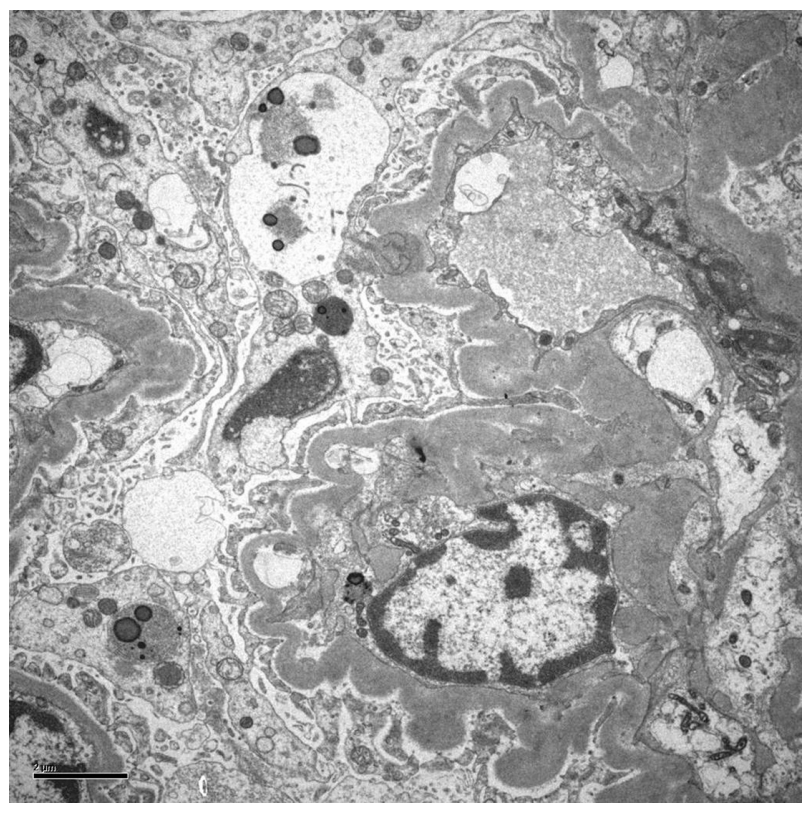

Figure 4 Electronmicrograph of a glomerulus that shows wrinkling of the capillary loops with endothelial cell swelling consistent with a diagnosis of pre-eclampsia (original magnification $\times 5800$ ).

improved, and her serum creatinine decreased to a value of $0.92 \mathrm{mg} / \mathrm{dL}(81.3 \mu \mathrm{mol} / \mathrm{L})$ and uric acid to $4.6 \mathrm{mg} / \mathrm{dL}$ $(274 \mu \mathrm{mol} / \mathrm{L})$. A spot urine protein to creatinine ratio was noted to be $1: 2$. She was subsequently discharged on oral hydralazine and labetalol.

\section{Discussion}

Severe pre-eclampsia is one of the most ominous complications of pregnancy. Pre-eclampsia that occurs early in pregnancy is more severe with poorer perinatal outcomes. In addition,

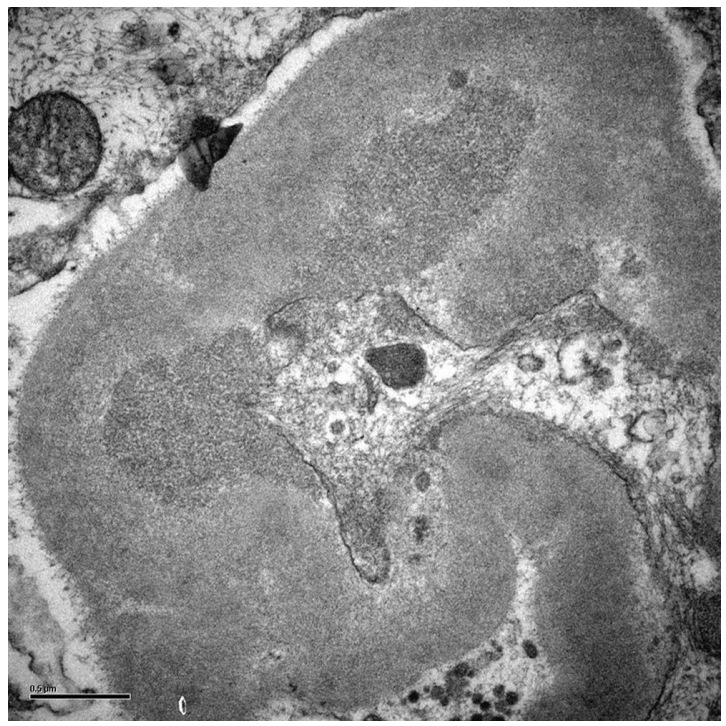

Figure 5 Electronmicrograph of a glomerulus demonstrating dense granular deposits in the mesangium (original magnification $\times 24,500$ ). 
pre-eclampsia tends to occur earlier and is more severe in women with primary renal disease. ${ }^{1,2}$ Often, it is difficult to diagnose an underlying renal disease in women who display severe pre-eclampsia or severe gestational proteinuria. In an evaluation of 86 women who had severe proteinuria and/or hypertension during pregnancy, postpartum renal biopsies noted the presence of primary renal disease in 19 patients $(22.1 \%) .^{4}$ Eighteen of the 19 patients with renal disease had proteinuria, hypertension, or both, before 30 weeks gestation. ${ }^{4}$ This study proposed that women who exhibit pre-eclampsia before 30 weeks gestation and who exhibit proteinuria at 6 weeks postpartum have an indication for a postpartum renal biopsy. In a follow-up study of 84 patients with early-onset pre-eclampsia (before 37 weeks gestation), renal abnormalities were found in $67 \%$ and $63 \%$ of the primiparas and multiparous, respectively. ${ }^{5}$ It was concluded that a presumptive diagnosis of idiopathic pre-eclampsia was likely to be correct if it developed after 37 weeks gestation; however, in all other cases, there is a significant likelihood of an underlying primary renal disease. ${ }^{5}$

Kidney diseases may be silent before pregnancy and subsequently become unmasked during pregnancy. ${ }^{6}$ IgA nephropathy is the most common kidney disease that has been associated with early onset pre-eclampsia, but other diseases that have been described linked with pre-eclampsia include non-IgA mesangial proliferative glomerulonephritis, polycystic kidney disease, diabetic nephropathy, and reflux nephropathy. ${ }^{4,5}$ Given that $\operatorname{IgA}$ nephropathy is the most common primary glomerulonephropathy worldwide, it is not surprising that it would be the most common renal disease linked with pre-eclampsia. Moreover, subtle underlying kidney disease may predispose to pre-eclampsia itself, with a risk of developing superimposed pre-eclampsia between $20 \%$ and $40 \%$ in women with some form of chronic kidney disease. ${ }^{3}$

At first glance, the presence of hematuria in this patient may suggest the presence of a primary renal disease given that hematuria is not a usual finding in pre-eclampsia. For this patient, there was the confounding factor for the presence of hematuria inasmuch as the urine specimen had been obtained from a traumatically inserted Foley catheter. Furthermore, the observed RBCs were not dysmorphic in appearance. Microscopic hematuria is actually not unusual in pregnancy. ${ }^{6}$ In one study of 902 pregnant women, $20 \%$ had dipstick- positive hematuria; however, it was rarely associated with significant kidney disease. ${ }^{7}$

For this patient, determining the cause for her proteinuria had critical clinical implications. Given that she was early in gestation with poor potential viability of the fetus, a diagnosis of pre-eclampsia would have prompted termination of the pregnancy. On the other hand, if the cause for her proteinuria was due to a primary glomerular disease, supportive therapies for the pregnancy and specific therapies for the glomerular disease would have been instituted. This issue is confounded by the fact that pre-eclampsia can mimic a number of glomerular diseases that present with the signs and symptoms of pre-eclampsia and further, pre-eclampsia can develop and be superimposed on an underlying occult chronic kidney disease. Noninvasive ways to distinguish pre-eclampsia versus primary kidney disease by measuring rising circulating levels of placental growth factor, endoglin, and the soluble form of vascular endothelial growth factor receptor (sFlt-1) have been suggested, but these assays are not clinically available currently and some studies have shown conflicting results. ${ }^{8}$ Thus, performing a renal biopsy was the only way to definitively determine the cause for the proteinuria and renal dysfunction and make a critical decision of whether to continue or terminate the pregnancy.

Performing kidney biopsies during pregnancy to differentiate pre-eclampsia from an underlying renal disease has been controversial. ${ }^{9}$ Renal biopsies in pregnant patients have been reported since the 1950s. There are theoretical concerns that increased blood flow during pregnancy would increase biopsy complications. ${ }^{10}$ Early reports suggested there was increased risking of bleeding complications in renal biopsies performed in pregnant patients, but these observations have been disputed by later studies. ${ }^{11-14}$ Packham and Fairley reported on 111 renal biopsies in 104 pregnant women before 29 weeks of gestation, which confirmed that there were no differences in biopsy risk between pregnant patients and the general population. ${ }^{14}$ A more recent study examined 20 women who underwent renal biopsy during pregnancy. ${ }^{13}$ Only one patient had transient hematuria postbiopsy. More importantly, for 9 of the 20 patients, the histologic results of the renal biopsy led to an immediate change in therapy. The authors of this study suggested that kidney biopsies should only be performed if knowledge of renal histology may lead to therapeutic intervention that would enable pregnancy to progress to fetal viability. This extends the previous recommendation by Lindheimer et $\mathrm{al}^{15}$ that renal biopsy is indicated in pregnant patients with unexplained nephroticrange proteinuria or sudden renal failure before 32 weeks gestation. Improvement in preterm neonatal survival over the past 20 years has led to lowering gestational age limit to 28 weeks. Biopsy after 32 weeks is generally not recommended, as by this time, the fetus can be safely delivered and a postpartum renal biopsy can be performed if parameters such as proteinuria or kidney function do not improve. ${ }^{13,15}$ Pre-eclamptic proteinuria may take several weeks to subside, 
and in women who develop pre-eclampsia before 30 weeks and continue to have proteinuria at 6 weeks postpartum, a renal biopsy is recommended. ${ }^{4}$

The patient in this case report had fulfilled the criterion where the results of a renal biopsy had critical clinical consequences. There was histologic evidence of both preeclampsia and IgA nephropathy. The rapid improvement in renal function and resolution of the nephrotic syndrome after the demise of the fetus suggest that pre-eclampsia was the primary cause for her renal dysfunction. The discovery of the underlying IgA nephropathy explains the early onset and severity of her pre-eclampsia.

\section{Disclosure}

There are no conflicts of interest for the authors of this manuscript.

\section{References}

1. Weiner CP. The clinical spectrum of preeclampsia. Am J Kidney Dis. 1987;9(4):312-316.

2. Paller MS. Hypertension in pregnancy. J Am Soc Nephrol. 1998;9(2): 314-321.

3. Krane NK, Hamrahian M. Pregnancy: kidney diseases and hypertension. Am J Kidney Dis. 2007;49(2):336-345.
4. Murakami S, Saitoh M, Kubo T, Koyama T, Kobayashi M. Renal disease in women with severe pre-eclampsia or gestational proteinuria. Obstet Gynecol. 2000;96(6):945-949.

5. Ihle BU, Long P, Oats J. Early onset pre-eclampsia: recognition of underlying renal disease. Br Med J (Clin Res Ed). 1987;294(6564):79-81.

6. Bernheim J, Plotkin E, Berheim J, Korzets Z. It looks like, it smells like but is it just pre-eclampsia? Nephrol Dial Transplant. 2005;20(2): 451-452.

7. Brown MA, Holt JL, Mangos GJ, Murray N, Curtis J, Homer C. Microscopic hematuria in pregnancy: relevance to pregnancy outcome. Am J Kidney Dis. 2005;45(4):667-673.

8. deVivo A, Baviera G, Giordano D, Todarello G, Corrado F, D'anna R. Endoglin, PIGF and sFlt-1 as markers for predicting pre-eclampsia. Acta Obset Gynecol Scand. 2008;87:832-842.

9. Pandya BK, Gibson SP, Robertson IG. Nephrotic syndrome in early pregnancy-is renal biopsy always necessary? Nephrol Dial Transplant. 2002;17(4):672-674.

10. Hou S. Pregnancy in women with chronic renal disease. N Engl J Med. 1985;312(13):836-839.

11. McCartney CP. Pathological anatomy of acute hypertension of pregnancy. Circulation. 1964;30 Suppl 2:37-42.

12. Schewitz LJ, Friedman IA, Pollak VE. Bleeding after renal biopsy in pregnancy. Obstet Gynecol. 1965;26:295-304.

13. Day $\mathrm{C}$, Hewins $\mathrm{P}$, Hildebrand $\mathrm{S}$, et al. The role of renal biopsy in women with kidney disease identified in pregnancy. Nephrol Dial Transplant. 2008;23(1):201-206.

14. Packham D, Fairley KF. Renal biopsy: indications and complications in pregnancy. Br J Obstet Gynaecol. 1987;94(10):935-939.

15. Lindheimer MD, Davison JM. Renal biopsy during pregnancy 'to $\mathrm{b}$... or not to b ...?'. Br J Obstet Gynaecol. 1987;94(10):932-934.
Pathology and Laboratory Medicine International

\section{Publish your work in this journal}

Pathology and Laboratory Medicine International is a peer-reviewed open access journal focusing on innovative basic research and translational research related to pathology or human disease. The journal includes original research, updates, case reports, reviews and commentaries on current controversies. The Academic Sponsor

\section{Dovepress}

of this journal is the Chinese American Pathology Association (CAPA). The manuscript management system is completely online and includes a very quick and fair peer-review system. Visit http://www.dovepress.com/testimonials.php to read real quotes from published authors.

Submit your manuscript here: http://www.dovepress.com/pathology-and-laboratory-medicine-international-journal 